\title{
CFTR mutation distribution among U.S. Hispanic and African American individuals: Evaluation in cystic fibrosis patient and carrier screening populations
}

Elaine A. Sugarman, $M S^{1}$, Elizabeth M. Rohlfs, $P h D^{1}$, Lawrence M. Silverman, $P h D^{2}$, and Bernice A. Allitto, $P h D^{1}$

\begin{abstract}
Purpose: We reviewed CFTR mutation distribution among Hispanic and African American individuals referred for CF carrier screening and compared mutation frequencies to those derived from CF patient samples. Methods: Results from CFTR mutation analyses received from January 2001 through September 2003, were analyzed for four populations: Hispanic individuals with a CF diagnosis $(n=159)$ or carrier screening indication $(n=15,333)$ and African American individuals with a CF diagnosis $(n=108)$ or carrier screening indication $(n=8,973)$. All samples were tested for the same 87 mutation panel. Results: In the Hispanic population, 42 mutations were identified: 30 in the patient population (77.5\% detection rate) and 33 among carrier screening referrals. Five mutations not included in the ACMG/ACOG carrier screening panel (3876delA, W1089X, R1066C, S549N, 1949del84) accounted for $7.55 \%$ detection in patients and $5.58 \%$ among carriers. Among African American referrals, 33 different mutations were identified: 21 in the patient population (74.4\% detection) and 23 in the carrier screening population. Together, A559T and $711+5 \mathrm{G}>\mathrm{A}$ were observed at a detection rate of $3.71 \%$ in $\mathrm{CF}$ patients and $6.38 \%$ in carriers. The mutation distribution seen in both the carrier screening populations reflected an increased frequency of mutations with variable expression such as D1152H, R117H, and L206W. Conclusions: A detailed analysis of CFTR mutation distribution in the Hispanic and African American patient and carrier screening populations demonstrates that a diverse group of mutations is most appropriate for diagnostic and carrier screening in these populations. To best serve the increasingly diverse U.S. population, ethnic-specific mutations should be included in mutation panels. Genet Med 2004:6(5):392-399.
\end{abstract}

Key Words: cystic fibrosis, Hispanic, African American, CFTR mutations, carrier screening

Classic cystic fibrosis presents with chronic pulmonary disease, pancreatic insufficiency, male infertility, and elevated sweat electrolyte concentrations. ${ }^{1}$ Although clinical expression of cystic fibrosis (CF) may vary, most affected individuals experience substantial morbidity and require lifelong care. ${ }^{1,2}$ With an incidence of $1: 3,200,{ }^{3} \mathrm{CF}$ is frequently cited as being one of the most common autosomal recessive disorders among Caucasians, yet its incidence among other ethnic groups is appreciable as well. One in 9,200 individuals of Hispanic descent and 1 in 15,000 African Americans are affected with CF. ${ }^{3}$

In 2001, the American College of Medical Genetics (ACMG) and the American College of Obstetricians and Gynecologists (ACOG) issued a joint statement recommending that CF carrier screening be offered to individuals of Ashkenazi Jewish or

From the ${ }^{1}$ Genzyme Corporation, Genzyme Genetics, Molecular Diagnostic Laboratory, Westborough, Massachusetts; and ${ }^{2}$ University of Virginia, Department of Pathology, Charlottesville, Virginia.

Elaine A. Sugarman, MS, Genzyme Genetics, Molecular Diagnostic Laboratory, 3400 Computer Drive, Westborough, MA 01581.

Received: May 3, 2004.

Accepted: June 28, 2004.

DOI: 10.1097/01.GIM.0000139503.22088.66
Caucasian descent and be made available to individuals of other ethnic and racial groups. ${ }^{4,5}$ The challenges cited in designing, and now in implementing, a general population screening program for $\mathrm{CF}$ include the variable prevalence of CFTR mutations among different ethnic and racial groups, the ethnic heterogeneity and increasing admixture of the U.S. population, and the difficulty in accurately assessing an individual's ethnic background for inclusion or exclusion from screening criteria. ${ }^{4}$ The ethnic heterogeneity and diversity of the U.S. population continues to grow. From 1970 to 2002, the White non-Hispanic population, decreased from $83 \%$ to $69 \%$ of the total U.S. population. ${ }^{6}$ In 2002, the Hispanic population comprising $13.5 \%{ }^{7}$ of the total United States population became the largest minority in the U.S. followed by the Black population with almost $13 \% .{ }^{8}$ In addition, $11.4 \%$ of the population is foreign born and $52.2 \%$ of the foreign born are from Latin America. ${ }^{9}$

Although the ACMG/ACOG recommended CF carrier screening panel was designed to primarily serve the recommended Caucasian and Ashkenazi Jewish screening populations, the possible need for inclusion of ethnic-specific mutations to serve regional populations has been recognized by the $\mathrm{ACMG}^{10,11}$ and recommended by others ${ }^{12,13}$ as necessary to 
best serve the panethnic U.S. population. Selection of ethnic specific mutations for inclusion in mutation panels requires collection and assessment of data from these populations.

Limited carrier screening data exists for CFTR mutation frequency among African American and Hispanic populations. ${ }^{14,15}$ Given our experience in receiving specimens from over 15,000 Hispanic individuals and almost 9,000 African American individuals for CF carrier screening, we sought to provide data regarding $C F T R$ mutation frequencies in these populations and to compare the CFTR mutation frequency data from these carrier screening populations with that of $\mathrm{CF}$ patient samples analyzed for the same 87 mutations. In this study, we contribute to the data on CFTR mutation frequency among the two largest minorities in the U.S. and provide information useful in designing mutation panels to best serve the increasingly diverse U.S. population.

\section{MATERIALS AND METHODS}

\section{Patient samples}

Among individuals referred for CFTR mutation analysis from January 2001 through September 2003, results from four patient populations were analyzed: Hispanic individuals with either a clinical diagnosis of CF $(n=159)$ or referred for carrier screening $(n=15,333)$ and African American individuals with a clinical CF diagnosis $(n=108)$ or referred for carrier screening $(n=8,973)$. Patient ethnic background and indication for testing were provided by the referring physician. Carrier screening refers to carrier tests performed for individuals with a general population carrier risk and excludes individuals with increased risk factors such as family history of CF or echogenic bowel. The CF patient population is derived from individuals referred with an indication of "known affected" and excludes individuals referred with a "suspected diagnosis" indication. Affected siblings were removed from the CF patient analyses.

Among Hispanic patients with a clinical diagnosis of CF, the age at testing ranged from 1 month to 45 years with 1 year of age being the most frequent age for referral, whereas the average age was 10.1 years. In the affected African American population, the age at testing had a similar range to that of Hispanics (1 month to 46 years), but the most frequent age for referral was later, 8 years, with a population average of 13.8 years.

Geographic distribution varied between affected and carrier screening referrals. Among Hispanic affected patients, samples were referred from 25 states across the U.S. with $\approx 40 \%$ from California, followed by New York (9.3\%), Texas (8.7\%) and Florida $(7.4 \%)$. In contrast, carrier screening referrals came from 42 different states with New York and Florida being the most frequent origin of referrals (34\% and 24\%). Among African American individuals, New York was the most frequent site of referral for both groups; affected individuals were referred from 26 different states, whereas carrier screening referrals came from 42 different states.

\section{Mutations}

All individuals were initially tested for the same panel of 87 mutations. Specimens positive for D1270N (see later) or I148T in the absence of 3199del6 were reclassified as negative for the purpose of this analysis. Specimens identified as I148T positive before the start of 3199del6 reflex testing are included in the analysis because their disease causing status is unknown.

\section{7 mutation panel}

The following mutations were included in the panel: $\Delta \mathrm{F} 508$, $\Delta \mathrm{F} 311, \Delta \mathrm{I} 507, \mathrm{~A} 455 \mathrm{E}, \mathrm{A} 559 \mathrm{~T}, \mathrm{C} 524 \mathrm{X}, \mathrm{D} 1152 \mathrm{H}, \mathrm{D} 1270 \mathrm{~N}$, E60X, G178R, G330X, G480C, G542X, G551D, G85E, G91R, I148T, K710X, L206W, M1101K, N1303K, P574H, Q1238X, Q359K/T360K, Q493X, Q552X, Q890X, R1066C, R1158X, R1162X, R117C, R117H, R1283M, R334W, R347H, R347P, R352Q, R553X, R560T, S1196X, S1251N, S1255X, S364P, S549I, S549N, S549R, T338I, V520F, W1089X, W1282X, Y1092X, Y563D, 1078delT, 1161delC, 1609delCA, 1677delTA, $1717-1 \mathrm{G}>\mathrm{A}, \quad 1812-1 \mathrm{G}>\mathrm{A}, \quad 1898+1 \mathrm{G}>\mathrm{A}, \quad 1898+5 \mathrm{G}>\mathrm{T}$, 1949del84, 2043delG, 2143delT, 2183delAA $>$ G, 2184delA, 2307insA, 2789+5G $>$ A, 2869insG, 3120+1G $>$ A, 3120G $>$ A, 3659delC, 3662delA, 3791delC, 3821delT, 3849+10kbC $>$ T, 3849+4A $>$ G, 3905insT, 394delTT, 405+1G $>$ A, 405+3A $>$ C, 444delA, 574delA, $621+1 \mathrm{G}>\mathrm{T}, 711+1 \mathrm{G}>\mathrm{T}, 711+5 \mathrm{G}>\mathrm{A}$, $712-1 \mathrm{G}>\mathrm{T}, 3876 \mathrm{delA}$

\section{CFTR mutation analysis}

Genomic DNA was extracted from peripheral blood lymphocytes, buccal cell swabs, or bloodspots by Qiagen QIAmp 96 DNA Blood Kit. Specimens were tested for 87 mutations by a pooled allele-specific oligonucleotide (ASO) hybridization method as previously described. ${ }^{16,17}$ Two multiplex chain reactions (PCR) were used to amplify 19 regions of the CFTR gene. The amplified PCR products were immobilized on nylon positively charged membrane and hybridized with groups of radioactive probes. Individual mutation identification of poolpositive samples was made by individual ASO hybridization to normal or mutant alleles.

\section{Ascertainment bias among CF patient population}

As described previously, ${ }^{17}$ our laboratory experiences ascertainment bias among CF patient referrals. This bias is the result of a portion of patients being tested in a tiered approach where initial mutation analysis is performed at another laboratory and then patients who are not fully informative for the common mutations are sent to our laboratory for expanded mutation analysis. An example of this practice is described by Kharrazzi et al. ${ }^{18}$ The use of this tiered approach by some physicians results in our CF patient population having a lower frequency of the common $\Delta$ F508 mutation and a resulting lower overall detection rate. To approximate the detection rate, it is necessary to correct for the lower $\Delta \mathrm{F} 508$ frequency and this was done by comparison with frequencies reported for populations presumed to be free of ascertainment bias. ${ }^{19,20}$ Conversely, such referral practices predict an over-ascertain- 
ment of less common mutations though attempts to correct for this demonstrate differences between our population and an unbiased comparison population to be minimal. Ascertainment bias is not expected or observed among the carrier screening populations.

\section{D1270N/R74W analysis}

A subset of 192 D1270N-positive samples derived from this sample set as well as samples received for a variety of indications and ethnicities were analyzed for the R74W sequence change using LightCycler (Roche) amplification and melting curve analysis.

The $10-\mu \mathrm{L}$ amplification reaction contained $\approx 100$ ng genomic DNA, 10× LightCycler DNA Master Hybridization Probes mix, 5 pmol of each primer, 2 pmol of each fluorescent probe and 4 $\mathrm{mmol} / \mathrm{L}$ of magnesium chloride. One probe (5'-AGAGCTGGCTTCAAAGAAAAATCCTAAACTC-3') was labeled on the 3 ' end with fluorescein and the other probe (5'-TAATGCCCTTCGGCGATGT-3'), which spanned nucleotide 352, was labeled on the 5 ' end with LC-Red640. Samples were amplified by an initial 30 -second incubation at $95^{\circ} \mathrm{C}$ followed by 45 cycles of repeated denaturation $\left(0\right.$ seconds at $\left.95^{\circ} \mathrm{C}\right)$, annealing $\left(10\right.$ seconds at $\left.55^{\circ} \mathrm{C}\right)$, and extension $\left(5\right.$ seconds at $\left.72^{\circ} \mathrm{C}\right)$. Amplification was monitored by the measurement of emitted fluorescence at the end of each annealing step. Melting curve analysis was performed by an increase to $95^{\circ} \mathrm{C}$ for 30 seconds followed by 1 minute at $40^{\circ} \mathrm{C}$ then heating to $80^{\circ} \mathrm{C}$ during which time the melting curve was recorded. The melting curves allowed for differentiation between the $\mathrm{C}$ or T nucleotide at position 352 .

\section{Statistical analysis}

The differences between the $\Delta$ F508 frequency in the Hispanic carriers from this study and the $\Delta$ F508 frequency in the California registry ${ }^{20}$ and the detection rates were tested using the Pearson Chi-square statistic. Exact inference was performed using StatXact (Cytel Software Corporation) with a significance level of $5 \%$.

Comparisons between observed carrier frequencies and expected frequencies used the one-sample test of proportions as implemented in StatXact (Cytel Software Corporation).

\section{RESULTS}

From January 2001 through July 2003, 74\% of CF carrier screening referrals to our laboratory were for individuals whose ethnicity was identified as Ashkenazi Jewish or Caucasian while the remaining $26 \%$ reported an ethnicity of Hispanic (9\%), African American (5\%), Asian (4\%), or Mixed/ Other/Unknown ethnicity (8\%). Individuals indicating more than one race/ethnicity (e.g., both African American and Caucasian) or an ethnicity not included in the classifications (e.g., Filipino) or not providing information regarding ethnicity were combined in the Mixed/Other/Unknown category.

\section{Hispanic CF patient population}

The distribution of the 42 different mutations identified in the Hispanic population is shown in Table 1. Among 318 CF patient chromosomes, 30 mutations were identified with $\Delta \mathrm{F} 508, \mathrm{G} 542 \mathrm{X}, \mathrm{R} 334 \mathrm{~W}, 3120+1 \mathrm{G}>\mathrm{A}, \mathrm{W} 1089 \mathrm{X}, 3876$ delA, and $\mathrm{R} 1066 \mathrm{C}$ representing $52.52 \%$ of the total. An additional 7 mutations were identified 2 to 3 times and 16 mutations were found once. Of the 30 different mutations identified in this group, 18 are included in the ACMG/ACOG recommended screening panel and 12 are not (Table 3 ). The 12 non-ACMG/ ACOG panel mutations accounted for $9.72 \%$ detection among CF patient chromosomes.

Overall, the 30 mutations resulted in a detection rate of $62.20 \%$. The $\Delta$ F508 mutation was identified on 118 of 318 (37.11\%) Hispanic CF patient chromosomes. This is lower than the $52.46 \%$ (447/852 chromosomes) observed among Hispanic patients in the California Cystic Fibrosis Patient Registry. ${ }^{20}$ When the overall detection rate is corrected using the California registry as a source of unbiased $\Delta \mathrm{F} 508$ frequency, the corrected detection rate is $77.55 \%$.

\section{Hispanic CF carrier screening population}

In the Hispanic carrier screening population $(n=15,333)$, 33 different mutations were found among the 287 carriers (1/53) identified (Table 1). The most prevalent mutations were as follows: $\Delta \mathrm{F} 508, \mathrm{D} 1152 \mathrm{H}, \mathrm{R} 117 \mathrm{H}, \mathrm{G} 542 \mathrm{X}, \mathrm{L} 206 \mathrm{~W}$, I148T (3199del6 status unknown), $\Delta \mathrm{I} 507$, R1066C, R553X, $3849+10 \mathrm{kbC}>\mathrm{T}$, and $\mathrm{R} 334 \mathrm{~W}$ representing $83.72 \%$ of the total identified. An additional 10 mutations were identified 2 to 5 times, and 12 others were identified once. Of the 33 different mutations identified among carriers, 16 are included in the ACMG/ACOG-recommended screening panel and 18 are not included (Table 3 ).

The $\Delta \mathrm{F} 508$ frequency observed in the carrier screening population $(47.39 \%)$ is not statistically significantly different $(P=$ 0.15 ) from the $52.5 \%$ observed in the California patient registry. This supports the contention that the screening population is not influenced by ascertainment bias. Assuming $\approx 77 \%$ detection for the mutations analyzed and an observed carrier frequency of $1 / 53$, if one corrects to a $100 \%$ detection, then the observed carrier frequency would be $1 / 43$, which is significantly different from the $1 / 48$ predicted by disease incidence $(P$ $=0.0052) .^{3}$ This difference may be due to sample size and the increased number of variable mutations identified among carriers.

The mutation distribution among carriers varied from that seen in the patient population. $\Delta \mathrm{F} 508$ was the most common mutation in both groups. With the exception of W1089X, the next 6 most frequent mutations in the patient population (G542X, R334W, 3120+1G>A, 3876delA, W1089X, and $\mathrm{R} 1066 \mathrm{C})$ were all seen in the carrier population at frequencies of $1.4 \%$ to $4.2 \%$. The W1089X mutation, which accounted for $2.2 \%$ detection among CF patients, was not seen in the carrier population. In the carrier screening group, 4 mutations, $\mathrm{D} 1152 \mathrm{H}, \mathrm{R} 117 \mathrm{H}, \Delta \mathrm{I} 507$, and L206W, had frequencies of $3.8 \%$ 
Table 1

CFTR mutation distribution among Hispanic CF patients and carrier screening referrals

\begin{tabular}{|c|c|c|c|c|}
\hline \multirow[b]{2}{*}{ CFTR Mutation Identified } & \multicolumn{2}{|c|}{ CF Patients } & \multicolumn{2}{|c|}{ Carrier Screening Referrals } \\
\hline & $\begin{array}{c}\text { \# of } \\
\text { CF Chromosomes }\end{array}$ & $\begin{array}{c}\% \\
\text { Detection }\end{array}$ & $\begin{array}{c}\text { \# of } \\
\text { Carrier Screen Referrals }\end{array}$ & $\begin{array}{c}\% \text { of } \\
\text { Positive Carriers }\end{array}$ \\
\hline$\Delta \mathrm{F} 508^{a}$ & 118 & $37.11^{c}$ & 136 & 47.39 \\
\hline G542X $\mathrm{X}^{a}$ & 11 & 3.46 & 12 & 4.18 \\
\hline $\mathrm{R} 334 \mathrm{~W}^{a}$ & 11 & 3.46 & 6 & 2.09 \\
\hline $3120+1 \mathrm{G}>\mathrm{A}^{a}$ & 7 & 2.20 & 5 & 1.74 \\
\hline $3876 \mathrm{delA}^{b}$ & 7 & 2.20 & 4 & 1.39 \\
\hline $\mathrm{W} 1089 \mathrm{X}^{b}$ & 7 & 2.20 & & \\
\hline $\mathrm{R} 1066 \mathrm{C}^{b}$ & 6 & 1.89 & 9 & 3.14 \\
\hline $3849+10 \mathrm{kbC}>\mathrm{T}^{a}$ & 3 & 0.94 & 6 & 2.09 \\
\hline $\mathrm{R} 1162 \mathrm{X}^{a}$ & 2 & 0.63 & 5 & 1.74 \\
\hline $\mathrm{G}^{6} 8 \mathrm{E}^{a}$ & 2 & 0.63 & 3 & 1.05 \\
\hline $\mathrm{S} 549 \mathrm{~N}^{b}$ & 2 & 0.63 & 2 & 0.70 \\
\hline $711+1 \mathrm{G}>\mathrm{T}^{a}$ & 2 & 0.63 & 1 & 0.35 \\
\hline $2789+5 \mathrm{G}>\mathrm{A}^{a}$ & 2 & 0.63 & 1 & 0.35 \\
\hline $1949 \mathrm{del} 84^{b}$ & 2 & 0.63 & 1 & 0.35 \\
\hline $\mathrm{R} 117 \mathrm{H}^{a}$ & 1 & 0.31 & 14 & 4.88 \\
\hline$\Delta \mathrm{I} 507^{a}$ & 1 & 0.31 & 11 & 3.83 \\
\hline $\mathrm{R}_{553 \mathrm{X}^{a}}$ & 1 & 0.31 & 7 & 2.44 \\
\hline$\Delta \mathrm{F} 311^{b}$ & 1 & 0.31 & 1 & 0.35 \\
\hline $1078 \operatorname{delT}^{a}$ & 1 & 0.31 & 1 & 0.35 \\
\hline $621+1 G>T^{a}$ & 1 & 0.31 & 1 & 0.35 \\
\hline $3659 \operatorname{delC}^{a}$ & 1 & 0.31 & 1 & 0.35 \\
\hline $\mathrm{Q}^{2} 90 \mathrm{X}^{b}$ & 1 & 0.31 & 1 & 0.35 \\
\hline $\mathrm{G}_{551 D^{a}}$ & 1 & 0.31 & & \\
\hline $1812-1 \mathrm{G}>\mathrm{A}^{b}$ & 1 & 0.31 & & \\
\hline I148T +3199 del $^{a}$ & 1 & 0.31 & & \\
\hline $\mathrm{A} 559 \mathrm{~T}^{b}$ & 1 & 0.31 & & \\
\hline $1717-1 \mathrm{G}>\mathrm{A}^{a}$ & 1 & 0.31 & & \\
\hline 3905 ins $^{b}$ & 1 & 0.31 & & \\
\hline $3821 \mathrm{delT}^{b}$ & 1 & 0.31 & & \\
\hline $\mathrm{G} 178 \mathrm{R}^{b}$ & 1 & 0.31 & & \\
\hline $\mathrm{D} 1152 \mathrm{H}^{b}$ & & & 18 & 6.27 \\
\hline $\mathrm{L}^{206 \mathrm{~W}^{b}}$ & & & 11 & 3.83 \\
\hline I148T (3199del6 status unknown) ${ }^{a}$ & & & 10 & 3.48 \\
\hline $\mathrm{N} 1303 \mathrm{~K}^{a}$ & & & 4 & 1.39 \\
\hline $\mathrm{W} 1282 \mathrm{X}^{a}$ & & & 4 & 1.39 \\
\hline $\mathrm{R}_{117 \mathrm{C}^{b}}$ & & & 4 & 1.39 \\
\hline $\mathrm{R}^{2} 52 \mathrm{Q}^{b}$ & & & 2 & 0.70 \\
\hline $712-1 \mathrm{G}>\mathrm{T}^{b}$ & & & 2 & 0.70 \\
\hline $\mathrm{Y}_{1092 \mathrm{X}^{b}}$ & & & 1 & 0.35 \\
\hline $444 \mathrm{del}^{b}$ & & & 1 & 0.35 \\
\hline $\mathrm{S} 549 \mathrm{R}^{b}$ & & & 1 & 0.35 \\
\hline 1609delCA ${ }^{b}$ & & & 1 & 0.35 \\
\hline Negative for mutations analyzed & 120 & 37.74 & 15046 & \\
\hline Total & 318 & $62.20^{d}$ & 15333 & 100.00 \\
\hline
\end{tabular}

${ }^{a}$ Mutation included in the ACMG/ACOG Recommended Core Mutation Panel for general population CF carrier screening. ${ }^{4,5}$

${ }^{b}$ Mutation not included in the ACMG/ACOG Recommended Core Mutation Panel for general population CF carrier screening.

${ }^{c}$ Referral bias contributes to a lower than expected $\Delta \mathrm{F} 508$ frequency. See Discussion.

${ }^{d}$ Corrected overall detection rate $\approx 77 \%$. Referral bias contributes to a lower than expected $\Delta \mathrm{F} 508$ frequency. See Discussion. 
to $6.2 \%$, whereas the same mutations were either observed only once or not at all in the CF patient population. With the exception of $\Delta \mathrm{I} 507$, each of these mutations is associated with variable phenotypic expression ${ }^{21-26}$ and when paired with $\Delta$ F508 has been reported in individuals with cystic fibrosis as well as CAVD. ${ }^{24}$

\section{African American CF patient population}

Table 2 depicts the distribution of 33 CFTR mutations identified in the African American population. Among 216 African American CF patient chromosomes, 21 different mutations were identified. The most frequent mutations $(\Delta \mathrm{F} 508$, $3120+1 \mathrm{G}>\mathrm{A}, 2307 \mathrm{ins}$, and A559T) have been previously reported to be frequent in the African American population ${ }^{19}$ and represent $46.77 \%$ of the total. Eleven of the 21 mutations identified are included in the ACMG/ACOG-recommended panel. The 10 non-ACMG/ACOG mutations identified accounted for $7.41 \%$ detection among the African American CF patient chromosomes (Table 3 ).

In total, 21 mutations led to a detection rate of $57.41 \%$. This is lower than the $75 \%$ detection observed by Macek et al. ${ }^{19}$ in a presumably unbiased African American sample of 148 chromosomes. This underestimate is once again explained by the lower frequency of $\Delta$ F508 chromosomes: $31 \% \Delta$ F508 frequency observed compared to $48 \%{ }^{19}$ expected. Using a $48 \%$ $\Delta$ F508 frequency to approximate an unbiased population, the detection rate for the mutations analyzed in this population would be $74.4 \%$. This corrected detection rate is not significantly different from the $81 \%{ }^{17}$ previously derived in 202 African American chromosomes analyzed in our laboratory $(P=0.1259)$.

After $\Delta \mathrm{F} 508$, the next most-frequent mutations were $3120+1 \mathrm{G}>\mathrm{A}(8.8 \%), 2307 \mathrm{ins} \mathrm{A}(4.17 \%), \mathrm{A} 559 \mathrm{~T}$ (2.78\%), and R553X (1.39\%). The $3120+1 \mathrm{G}>\mathrm{A}$ frequency observed in this study was lower than the $13.8 \%$ we had observed in our earlier dataset; however, the difference is not significant $(P=0.1214)$. An additional 4 mutations (G551D, 1717-1G>A, G542X, $711+5 \mathrm{G}>\mathrm{A})$ were detected twice $(0.93 \%$ each), whereas 12 other mutations were identified on one chromosome each. Five of the twelve mutations identified once are considered to be "African American" mutations (3791delC, G330X, G480C, 444delA, and S1255X). ${ }^{19}$

\section{African American CF carrier screening population}

Among the 8,973 African American individuals referred for carrier screening, 23 different mutations were identified among 94 (1/95) carriers (Table 2). The most frequent mutations were $\Delta$ F508 $(52.1 \%), 3120+1 \mathrm{G}>\mathrm{A}(9.6 \%), \mathrm{A} 559 \mathrm{~T}$ (6.38\%), and R117H (5.32\%). The 2307insA mutation, which had a frequency of $>4 \%$ among CF patients, was not identified among carriers. Twelve mutations identified in the carrier screening population were not identified among the CF patient population. These include mutations known to be associated with variable phenotypic expression such as $\mathrm{R} 117 \mathrm{H},{ }^{21,22}$ $\mathrm{D} 1152 \mathrm{H},{ }^{23-25}$ and $3849+10 \mathrm{kbC}>\mathrm{T} .{ }^{27,28}$
Assuming $\approx 74 \%$ detection for the mutations analyzed and an observed carrier frequency of $1 / 95$, an adjustment to $100 \%$ detection would result in a carrier frequency of $1 / 76$, which is not significantly different than the expected $1 / 61^{3}$ based on the disease incidence $(P=0.1779)$.

\section{Reclassification of specimens positive for the D1270N sequence change}

Mutation analysis for all samples included D1270N. Comparison of D1270N chromosomes between African American CF patients and carrier screening referrals revealed a $>100$ fold increase among carriers (2 CF patient chromosomes: 228 CF carrier alleles). To investigate a potential modifying effect of R74W on the D1270N phenotype, we analyzed 192 D1270N-positive individuals for the presence of R74W. ${ }^{29} \mathrm{~Pa}$ tients were of varying ethnicities (46.4\% African American, 29.2\% Hispanic, 11.9\% Caucasian, 12.5\% Other/Mix/Not Provided) and indications (Table 4). Two individuals with the indication of carrier testing were homozygous for both D1270N and R74W. In addition, a 27-year-old Hispanic male with recurrent respiratory infections had the same genotype. Six individuals carried the genotype of a severe CF mutation (i.e., $\Delta$ F508), one copy of D1270N and one copy of R74W. Two of these individuals had the indication of carrier testing, two were affected with $\mathrm{CF}$, one was suspected of having $\mathrm{CF}$, and one was referred in followup to newborn screening. Among those samples $(n=167)$ received for carrier testing, $169 \mathrm{D} 1270 \mathrm{~N}$ alleles and 159 R74W alleles were detected. While we were unable to determine phase, overall $94 \%$ of individuals with a D1270N allele also carried an R74W allele. In this data set there is no apparent correlation between D1270N, R74W, and phenotype. The D1270N sequence change was therefore not included in analysis of data for the larger study and has subsequently been removed from our CF test.

\section{DISCUSSION}

The term Hispanic has been used to describe individuals originating from Latin America yet having diverse racial and ethnic backgrounds. ${ }^{30}$ Because Hispanic individuals may be of any race, the designation of Hispanic for purposes of genetic analyses has presented challenges and been the subject of discussion in the genetics literature. ${ }^{31,10}$ Although specific race or country of origin data are not available for the majority of patients referred for testing, there remains utility to making observations for the Hispanic population as a whole. Subdividing patients based on country of origin or race would result in an insufficient number of CF chromosomes from which to make observations. We have previously reported the identification of numerous mutations that are not considered Hispanic-specific, among CF chromosomes from Hispanic CF patients. ${ }^{17}$ The data from this current study support the similar conclusion from Heim et al., ${ }^{17}$ that to best serve the genetically heterogeneous Hispanic population, a panethnic mutation panel that includes mutations traditionally considered to be "Hispanic," "African American" as well as "Caucasian" is op- 
Table 2

CFTR mutation distribution among African-American CF patients and carrier screening referrals

\begin{tabular}{|c|c|c|c|c|}
\hline \multirow[b]{2}{*}{ CFTR Mutation Identified } & \multicolumn{2}{|c|}{ CF Patients } & \multicolumn{2}{|c|}{ Carrier Screening Referrals } \\
\hline & $\begin{array}{c}\text { \# CF } \\
\text { Chromosomes } \\
\end{array}$ & $\begin{array}{c}\% \\
\text { Detection } \\
\end{array}$ & $\begin{array}{c}\text { \# Carrier } \\
\text { Screen Referrals }\end{array}$ & $\begin{array}{c}\% \text { of } \\
\text { Positive Carriers } \\
\end{array}$ \\
\hline$\Delta \mathrm{F} 508^{a}$ & 67 & $31.02^{c}$ & 49 & 52.13 \\
\hline $3120+1 \mathrm{G}>\mathrm{A}^{a}$ & 19 & 8.80 & 9 & 9.57 \\
\hline 2307 insA $^{a}$ & 9 & 4.17 & & \\
\hline $\mathrm{A} 559 \mathrm{~T}^{b}$ & 6 & 2.78 & 6 & 6.38 \\
\hline $\mathrm{R}_{553 \mathrm{X}^{a}}$ & 3 & 1.39 & 2 & 2.13 \\
\hline $\mathrm{G}_{551 D^{a}}$ & 2 & 0.93 & 1 & 1.06 \\
\hline $1717-1 \mathrm{G}>\mathrm{A}^{a}$ & 2 & 0.93 & 1 & 1.06 \\
\hline G542X ${ }^{a}$ & 2 & 0.93 & 1 & 1.06 \\
\hline $711+5 G>A^{b}$ & 2 & 0.93 & & \\
\hline $3791 \mathrm{delC}^{b}$ & 1 & 0.46 & 2 & 2.13 \\
\hline $1812-1 \mathrm{G}>\mathrm{A}^{b}$ & 1 & 0.46 & 1 & 1.06 \\
\hline $\mathrm{G} 330 \mathrm{X}^{b}$ & 1 & 0.46 & 1 & 1.06 \\
\hline $\mathrm{G}_{480 \mathrm{C}^{b}}$ & 1 & 0.46 & 1 & 1.06 \\
\hline $444 \mathrm{delA}^{b}$ & 1 & 0.46 & & \\
\hline $\mathrm{S} 1255 \mathrm{X}^{b}$ & 1 & 0.46 & & \\
\hline $\mathrm{R} 1162 \mathrm{X}^{a}$ & 1 & 0.46 & & \\
\hline $\mathrm{R} 334 \mathrm{~W}^{a}$ & 1 & 0.46 & & \\
\hline $\mathrm{E} 60 \mathrm{X}^{b}$ & 1 & 0.46 & & \\
\hline $\mathrm{S} 549 \mathrm{R}^{b}$ & 1 & 0.46 & & \\
\hline $\mathrm{N} 1303 \mathrm{~K}^{a}$ & 1 & 0.46 & & \\
\hline $\mathrm{R} 60 \mathrm{~T}^{a}$ & 1 & 0.46 & & \\
\hline $\mathrm{R} 117 \mathrm{H}^{a}$ & & & 5 & 5.32 \\
\hline $\mathrm{D} 1152 \mathrm{H}^{b}$ & & & 3 & 3.19 \\
\hline $3849+10 \mathrm{kbC}>\mathrm{T}^{a}$ & & & 2 & 2.13 \\
\hline$\Delta \mathrm{F} 311^{b}$ & & & 2 & 2.13 \\
\hline $\mathrm{R} 1158 \mathrm{X}^{b}$ & & & 1 & 1.06 \\
\hline $\mathrm{R} 1066 \mathrm{C}^{b}$ & & & 1 & 1.06 \\
\hline$\Delta \mathrm{I} 507^{a}$ & & & 1 & 1.06 \\
\hline $2789+5 \mathrm{kbG}>\mathrm{A}^{a}$ & & & 1 & 1.06 \\
\hline $\mathrm{S} 364 \mathrm{P}^{b}$ & & & 1 & 1.06 \\
\hline $\mathrm{L}_{206 \mathrm{~W}^{b}}$ & & & 1 & 1.06 \\
\hline $405+3 \mathrm{~A}>\mathrm{C}^{b}$ & & & 1 & 1.06 \\
\hline S1255X $\mathrm{X}^{a}$ & & & 1 & 1.06 \\
\hline Negative for mutations analyzed & 92 & 42.59 & 8879 & \\
\hline Total & 216 & $57.41^{d}$ & 8973 & 100.00 \\
\hline
\end{tabular}

${ }^{a}$ Mutation included in the ACMG/ACOG Recommended Core Mutation Panel for general population CF carrier screening. ${ }^{4,5}$

${ }^{b}$ Mutation not included in the ACMG/ACOG Recommended Core Mutation Panel for general population CF carrier screening.

${ }^{c}$ Referral bias contributes to a lower than expected $\Delta$ F508 frequency. See Discussion.

${ }^{d}$ Corrected overall detection rate $\approx 74 \%$. Referral bias contributes to a lower than expected $\Delta$ F508 frequency. See Discussion. 
Table 3

Mutation identificaiton relative to ACMG/ACOG recommended screening panel

\begin{tabular}{cccc}
\hline Total No. of & No. of & & \\
Different & ACMG/ACOG & No. of Other & Detection Rate \\
Mutations & Mutations & Mutations & for Other \\
Identified & Detected & Detected & Mutations \\
\hline
\end{tabular}

Hispanic

$\begin{array}{lcccc}\text { CF patients } & 30 & 18 & 12 & 9.72 \%^{a} \\ \text { CF carriers } & 33 & 16 & 17 & \text { N/A } \\ \text { Combined }^{c} & 42 & 21 & 21 & \\ \text { frican American } & & & & \\ \text { CF patients } & 21 & 11 & 10 & 7.41 \%^{b} \\ \text { CF carriers }^{b} & 23 & 11 & 12 & \text { N/A } \\ \text { Combined }^{c} & 33 & 17 & 16 & \end{array}$

${ }^{a}$ Refer to Table 1 .

${ }^{b}$ Refer to Table 2 .

'Some mutations were identified in both CF patients and carriers, whereas others did not overlap.

timal. In the current study, 42 different mutations were identified among the Hispanic individuals (patients and carriers) tested and the most common mutations included those previously reported to be common among Hispanics, 3876delA, ${ }^{32}$ W1089X, ${ }^{17}$ as well as mutations considered frequent in African Americans $(3120+1 \mathrm{G}>\mathrm{A})^{19}$ and panethnic (e.g., G542X, $\Delta \mathrm{I} 507)$ populations. ${ }^{33}$ Although regional variation in overall detection rates may occur, these data provide general guidance when developing a panethnic mutation panel and information useful for genetic counseling purposes.

By directly comparing CFTR mutation distribution between $\mathrm{CF}$ chromosomes identified via affected patients and carrier screening, we have made a number of interesting observations. Although the overall carrier frequency observed in the carrier screening population did not differ significantly from that predicted by disease incidence in the African American population, it did differ in the Hispanic population. In addition, the distribution of the mutations identified differed among CF patient and carrier screening populations for both groups. In both the Hispanic and African American populations, mutations associated with a variable clinical phenotype such as

Table 4

Indications for 192 D1270N-positive patient samples

\begin{tabular}{lc}
\hline Indication & No. of Specimens \\
\hline Carrier testing-no family history & 153 \\
Carrier testing-family history & 9 \\
Carrier testing-abnormal fetal ultrasound findings & 5 \\
Known affected-CF diagnosis & 3 \\
Infertility & 5 \\
Suspected diagnosis (CF or pancreatitis) & 15 \\
Indication not provided & 2 \\
\hline
\end{tabular}

$\mathrm{R} 117 \mathrm{H}, \mathrm{D} 1152 \mathrm{H}$, and L206W were more common in the carrier screening population than the affected population. Similar findings of discrepant frequencies for these variable mutations are well known in the Caucasian population and are now confirmed among these minority populations as well. Each of these variable mutations has been reported in the literature in individuals with a diagnosis of cystic fibrosis, CAVD, and in unaffected carriers of 2 mutations. ${ }^{15,24,25,34}$ Geographic differences in the origin of the carrier versus patient referrals may also contribute to the variation in mutation distributions between the groups. The lack of detection in the carrier screening population of mutations identified among patients (e.g., $2307 \mathrm{del}$, W1089X) is not unexpected given the inherent variability in estimates of low-frequency mutations.

From direct comparison of patient and carrier screening populations tested for the same mutation panel, we also identified a $>100$-fold increase in the number of D1270N chromosomes among African American carriers as compared with African American CF patients. D1270N has been identified in

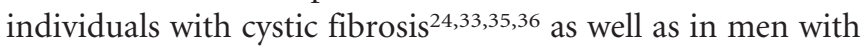
congenital absence of the vas deferens. ${ }^{24,37}$ Similar discrepancies in mutation frequency between carrier and patient populations are now well known for the R117H ${ }^{15}$ and $\mathrm{I}_{148 \mathrm{~T}^{38,39}}$ sequence changes, each of which has a cis-acting modifier influencing phenotype (5T $\mathrm{T}^{21}$ and 3199del6,40 respectively). There have been similar reports that R74W may be a potential modifier for the clinical phenotype of D1270N. ${ }^{29}$ The $\Delta \mathrm{F} 508 /$ D1270N-R74W genotype has been reported in a girl with CF symptoms, ${ }^{41}$ in 2 CF patients, 3 CBAVD patients, ${ }^{24}$ and a $27-$ year-old man with CBAVD, elevated sweat chlorides, recurrent respiratory infection, and rhinitis. ${ }^{35}$ Our study of 192 D1270Npositive specimens was not suggestive of a role for R74W as a modifying allele, and a definitive explanation for the variable D1270N frequencies remains unknown.

In the Hispanic population, our findings support the inclusion, minimally, of 3876delA, R1066C, S549N, and 1949del84 in a mutation panel. Although not yet identified among our carrier screening population, the W1089X mutation with a $2.2 \%$ frequency among CF patients would also be valuable. Together these 5 mutations accounted for $7.55 \%$ detection for the CF patient population and $5.58 \%$ among carriers. Similar recommendations have been made by other groups to add mutations that would increase detection in the Hispanic populatin. ${ }^{13,18,32}$ In the African American population, the A559T mutation was the 4 th most common mutation among CF patient chromosomes $(2.78 \%)$ and the third most frequent among CF carriers $(6.38 \%)$ and as such would warrant inclusion, with $711+5 \mathrm{G}>\mathrm{A}(0.93 \%)$, in any screening program serving an African American population. As with our previous dataset, ${ }^{17}$ we conclude that the populations benefited from being tested with a panethnic mutation panel that was not limited to mutations frequent in a given ethnic group. This is important, not only for the Hispanic population where individuals may be of numerous ethnic or racial backgrounds, but also for all panethnic populations given the increasing admixture and ethnic diversity of our society. ${ }^{6,13,42}$ 
With $14 \%$ of our carrier screening referrals being from Hispanic and African American individuals, and another 12\% from individuals with ethnicities other than the ACMG/ACOG recommended Caucasian or Ashkenazi Jewish, it is evident that clinicians are offering or making CF carrier screening available to a diverse population, many of whom choose testing. To best serve these individuals, a CFTR mutation panel that reflects diversity is necessary.

\section{ACKNOWLEDGMENTS}

We are thankful for the contributions of Nichole Napolitano and Toby Payeur and the technical and clinical staff at the Molecular Diagnostic Laboratory of Genzyme Genetics who are responsible for assay performance, technical review, and clinical review of patient results. We appreciate the assistance of Michelle Blalock, of the University of Virginia, for R74W analysis of D1270N-positive specimens and Stephen Lake for support with statistical calculations.

\section{References}

1. Welsh MJ, Ramsey BW, Accurso F, Cutting GR. Cystic Fibrosis. In: Scriver CR, Beaudet AL, Sly WS, Valle D, eds. The metabolic and molecular bases of inherited disease, 8th ed. New York: McGraw-Hill, 2001:5121-5188.

2. Cystic Fibrosis Foundation. Available at: http://www.CFF.org/ Accessed April 21, 2004 .

3. Hamosh A, Fitzsimmons SC, Macek M, Knowles MR, Rosenstein BJ, Cutting GR. Comparison of the clinical manifestations of cystic fibrosis in black and white patients. J Pediatr 1998;132:255-259.

4. Grody WW, Cutting GR, Klinger KW, Richards CS, Watson MS, Desnick RJ. Laboratory standards and guidelines for population-based cystic fibrosis carrier screening. Genet Med 2001;3:456-461.

5. American College of Obstetricians and Gynecologists, and American College of Medical Genetics. 2001. Preconception and prenatal carrier screening for cystic fibrosis. Clinical and Laboratory Guidelines. American College of Obstetricians and Gynecologists, Washington, DC.

6. U.S. Census Bureau, American Fact Finder. People: Race and Ethnicity. Diversity Continues to Grow in the U.S., 2003. Available at: http://factfinder.census.gov Accessed April 2, 2004.

7. Ramirez RR, de la Cruz P. The Hispanic Population in the United States: March 2002.Washington DC, U.S. Census Bureau, June 2003. Current Population Reports, P20-545.

8. McKinnon J. The Black Population in the United States: March 2002. Washington, DC, U.S. Census Bureau, April 2003. Current Population Reports, P20-541.

9. Schmidley D. The Foreign-Born Population in the United States: March 2002. Washington, D.C., U.S. Census Bureau, February 2003. Current Population Reports, P20-539.

10. Richards CS, Bradley LA, Amos J, Allitto BA, Grody WW, Maddalena A et al. Standards and guidelines for CFTR mutation testing. Genet Med 2002;4:379-391.

11. Watson MS, Cutting GR, Desnick RJ, Driscoll D, Klinger K, Mennuti M et al. Cystic fibrosis (CF) Couple Carrier Screening: 2004 Revision of American College of Medical Genetics Mutation Panel. Genet Med 2004;6:387-391.

12. Gilbert F. Cystic fibrosis carrier screening: Steps in the development of a mutation panel. Genet Test 2001;5:223-227.

13. Bobadilla JL, Macek M, Fine JP, Farrell PM. Cystic fibrosis: A worldwide analysis of CFTR Mutations - Correlation with incidence data and application to screening. Hum Mutat 2002;19:575-606.

14. Monaghan K, Bluhm D, Phillips M, Feldman GL. Preconception and prenatal cystic fibrosis carrier screening of African Americans reveals a higher carrier frequency and unanticipated frequencies for specific mutations. Genet Med 2004;6:141-144.

15. Witt DR, Schaefer C, Hallam P, Wi S, Blumberg B, Fishbach A et al. Cystic fibrosis heterozygote screening in 5,161 pregnant women. Am J Hum Genet 1996;58:823835 .

16. Shuber A, Skoletsky J, Stern R, Handelin B. Efficient 12-mutation testing in the CFTR gene: A general model for complex mutation analysis. Hum Mol Genet 1993; 2:153-158.

17. Heim RA, Sugarman EA, Allitto BA. Improved detection of cystic fibrosis mutations in the heterogeneous U.S. population using an expanded pan-ethnic mutation panel. Genet Med 2001;3:168-176.
18. Kharrazi M, Alper O, Young S, Pearl M, Graham S, Lorey F et al. Cystic fibrosis transmembrane regulator mutations in Hispanic Californians with cystic fibrosis. Am J Hum Genet 2003;73(5):A1424,413.

19. Macek M Jr, Mackova A, Hamosh A, Hilman BC, Selden RF, Lucotte G et al. Identification of common cystic fibrosis mutations in African-Americans with cystic fibrosis increases the detection rate to 75\%. Am J Hum Genet 1997;60:1122-1127.

20. Kharrazi M. Genetic Disease Branch, California Department of Health Services. 2/2004. Available at: http://www.dhs.ca.gov/pcfh/gdb/html/PDE/CFTable1.html Accessed April 8, 2004.

21. Kiesewetter S, Macek M, Davis C, Curristin SM, Chu C-S, Graham C et al. A mutation in CFTR produces different phenotypes depending on chromosomal background. Nat Genet 1993;5:274-278.

22. Massie RJH, Poplawski N, Wilcken B, Goldblatt J, Byrnes C, Robertson C. Intron-8 polythymidine sequence in Australasian individuals with CF mutations R117H and R117C. Eur Respir J 2001;17:1195-1200.

23. Feldmann D, Rochemaure J, Plouvier E, Magnier C, Chauve C, Aymard P. Mild course of cystic fibrosis in an adult with the D1152H mutation. Clin Chem 1995;45: 1675 .

24. Claustres M, Guittard C, Bozon D, Chevalier F, Verlingue C, Ferec C et al. Spectrum of CFTR mutations in cystic fibrosis and in congenital absence of the vas deferens in France. Hum Mutat 2000;16:143-156.

25. Feldmann D, Coudere R, Audrezet MP, Ferec C, Bienvenu T, Desgeourges $\mathrm{M}$ et al. CFTR genotypes in patients with normal or borderline sweat chloride levels. Hum Mutat 2003:22:340-347.

26. Rozen R, Ferreira-Rajabi L, Robb L, Colman N. L206W mutation of the cystic fibrosis gene, relatively frequent in French Canadians, is associated with atypical presentations of cystic fibrosis. Am J Med Genet 1995;57:437-9.

27. Highsmith WE, Burch L, Zhou Z, Olsen JC, Boat TE, Spock A et al. A novel mutation in the cystic fibrosis gene in patients with pulmonary disease but normal sweat chloride concentrations. N Engl J Med 1994;331:974-80.

28. Gilbert F, Li Z, Arzimanoglou I, Bialer M, Denning C, Gorvoy J et al. Clinical spectrum in homozygotes and compound heterozygotes inheriting cystic fibrosis mutation 3849+10kbC > T: Significance for geneticists. Am J Med Genet 1995;58: 356-359. [erratum appears in Am J Med Genet 1996;64:527].

29. Fanen P, Clain J, Labarthe R, Hulin P, Girodon E, Pagesy P et al. Structure-function analysis of a double-mutant cystic fibrosis transmembrane conductance regulator protein occurring in disorders related to cystic fibrosis. FEBS Lett 1999;452:371-374.

30. Grieco EM, Cassidy RC. Overview of Race and Hispanic Origin: Census 2000 Brief, Washington, D.C. U.S. Census Bureau, March 2001.

31. Arzimanoglou I, Tuchman A, Li Z, Gilbert F, Denning C, Valverde K et al. Cystic fibrosis carrier screening in Hispanics. Am J Hum Genet 1995;56:544-547.

32. Wong LJC, Wang J, Zhang YH, Hsu E, Heim R, Bowman CM et al. Improved detection of CFTR mutations in Southern California Hispanic CF patients. Hum Mutat 2001;18:296-307.

33. Estivill X, Bancells C, Ramos C, Biomed CF. Mutation Analysis Consortium. Geographic distribution and regional origin of 272 cystic fibrosis mutations in European populations. Hum Mutat 1997;10:135-154.

34. Rohlfs EM, Sugarman EA, Heim RA, Allitto BA. Frequency of carriers of two cystic fibrosis mutations in an apparently unaffected adult population. Genet Med 2001;3: 237.

35. Casals T, Bassas L, Ruiz-Romero J, Chillon M, Gimenex J, Ramos MD et al. Extensive analysis of 40 infertile patients with congenital absence of the vas deferens: in 50\% of cases only one CFTR allele could be detected. Hum Genet 1995;95:205-211.

36. Padoa C, Goldman A, Jenkins T, Ramsay M. Cystic fibrosis carrier frequencies in populations of African origin. J Med Genet 1999;36:41-44.

37. Anguiano A, Oates R, Amos J, Dean M, Gerrard B, Stewart C et al. Congenital bilateral absence of the vas deferens: a primary genital form of cystic fibrosis. JAMA 1992;267:1794-1797.

38. Rohlfs EM, Zhou Z, Sugarman EA, Heim RA, Pace RG, Knowles MR et al. The I148T CFTR mutation confers a variable phenotype and occurs on multiple haplotypes. Am J Hum Genet suppl 2001:69A.

39. Strom CM, Huang D, Buller A, Redman J, Crossley B, Anderson B et al. Cystic fibrosis screening using the College panel: Platform comparison and lessons learned from the first 20,000 samples. Genet Med 2002;4:289-296.

40. Rohlfs EM, Zhou Z, Sugarman EA, Heim EI, Pace RG, Knowles MR et al. The I148T CFTR allele occurs on multiple haplotypes: A complex allele is associated with cystic fibrosis. Genet Med 2002;4:319-323.

41. Cystic Fibrosis Mutation Data Base. http://www.genet.sickkids.on.ca/cftr/ Accessed on May 23, 2003.

42. Gilbert F, Schoelkopf J, Zhen L, Arzimanoglou I, Shaham M, Udey J Ethnic intermarriage and its consequences for cystic fibrosis carrier screening. Am J Prev Med 1995;11:251-255. 